\title{
CORRECTION OF FUNCTIONAL TRICUSPID INSUFFICIENCY BY MEANS OF A LIMITED POSTERIOR CROSSED SUTURE ANNULOPLASTY
}

\author{
Josep M. Caralps, MD, ${ }^{\mathrm{a}}$ Vicens Martí, MD, ${ }^{\mathrm{b}}$ Francesc Carreras, MD, ${ }^{\mathrm{b}}$ and Alfons Sualís, MD, ${ }^{\mathrm{b}}$ Barcelona, Spain
}

Functional tricuspid regurgitation (TR) occurs as a result of asymmetric dilatation and deformation of the tricuspid anulus owing to right ventricular enlargement.

From the Departments of Cardiac Surgery ${ }^{\mathrm{a}}$ and Cardiology, ${ }^{\mathrm{b}}$ Hospital de la Santa Creu i Sant Pau, and Clínica Quirón, ${ }^{a}$ Barcelona, Spain.

Received for publication Oct. 21, 1997; accepted for publication Dec. 23, 1997.

Address for reprints: Vicens Martí, MD, Department of Cardiac Surgery and Cardiology, Hospital de la Santa Creu i Sant Pau, Sant Antoni M. Claret 167, 08025 Barcelona, Spain.

J Thorac Cardiovasc Surg 1998;115:1378-81

Copyright (c) 1998 by Mosby, Inc.

$0022-5223 / 98 \$ 5.00+0 \quad \mathbf{1 2 / 5 4 / 8 8 6 8 8}$
Although TR may spontaneously regress after correction of left-sided valvular lesions, increasing experience shows that in the presence of significant insufficiency, tricuspid annuloplasty (TA) decreases postoperative morbidity and mortality. ${ }^{1,2}$ In the present report we describe a simple technique of TA for patients with significant TR. We evaluated the efficacy of the procedure by clinical and Doppler echocardiography at follow-up.

Patients. The study group comprised 34 patients (26 female and 8 male, aged $61 \pm 36$ years) who underwent TA for correction of TR. Isolated TR repair was performed in six patients in whom the valve had previously been repaired by the De Vega annuloplasty. Seventeen patients underwent concomitant mitral replacement, six a mitral-aortic valve replacement, and five an additional coronary bypass grafting. Nine patients had undergone a 

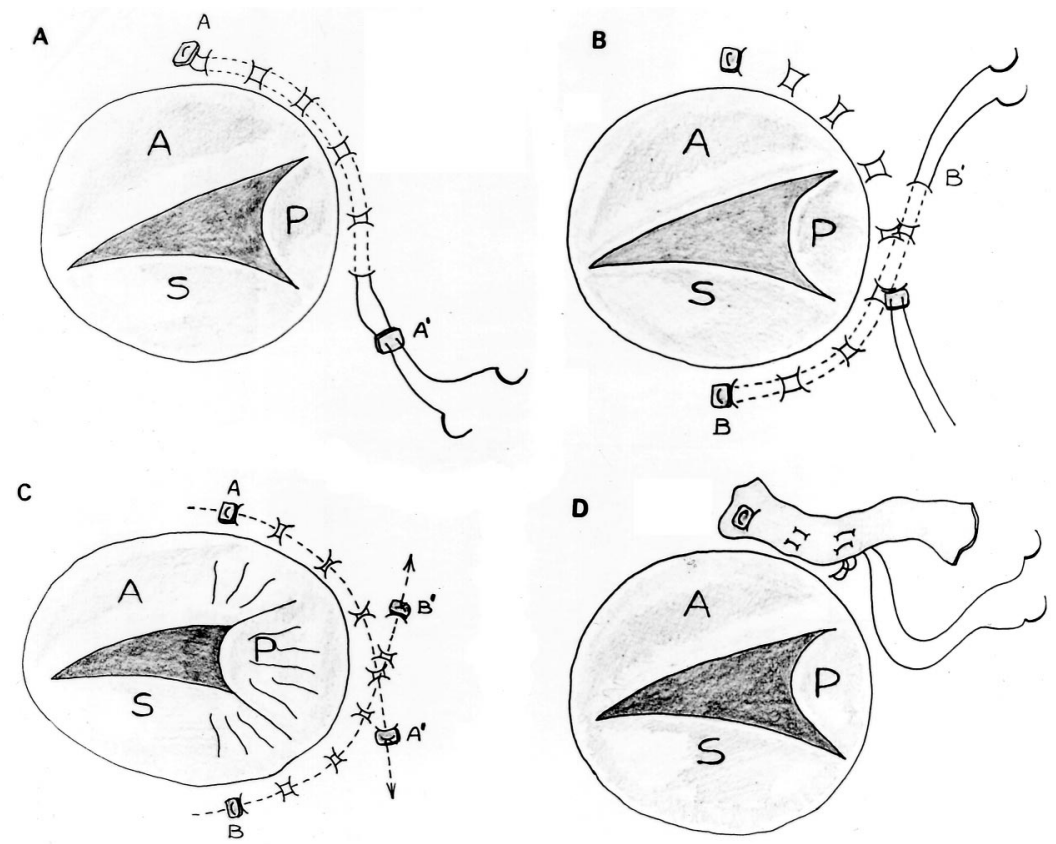

Fig. 1. Atrial view diagrams of the TA. A double-armed pledget suture is placed from the midportion of the anulus of the anterior leaflet to the midportion of the posteroseptal commissure (A). A second suture is then placed from the midportion of the septal leaflet anulus, crossing the previously placed suture at the midportion of the posterior leaflet, and ending at the level of the anteroposterior commissure (B and $\mathbf{C})$. A strip of autologous pericardium is sometimes used to reinforce the suture line (D) (see text). $A$, Anterior; $P$, posterior; $S$, septal.

previous valve procedure and seven patients had had two previous operations. Excluded from the study were those patients with organic tricuspid disease. Preoperatively, 18 patients were in functional class III of the New York Heart Association (NYHA) and the remaining 16 patients were in functional class IV. After the operation patients were followed up in the outpatient clinic for $2.2 \pm 1.7$ years (range 0.1 to 6.3 years).

Operative technique. The TA procedure consists of a doubled-armed pledget-supported suture that starts in the midportion of the anulus of the anterior leaflet (12 $\mathrm{o}^{\prime}$ clock). The stitches are placed deep in the anulus and run tangentially toward the base of the posterior leaflet, ending at the level of the posteroseptal commissure. A second doubled-armed suture starts in the midportion of the septal leaflet anulus (6 o'clock), runs posteriorly, crosses the previously placed suture at the midportion of the posterior leaflet, and ends at the level of the anteroposterior commissure. Both sutures are then firmly tied over a $3 \mathrm{~cm}$ plastic dilator. In cases in which the anulus diameter exceeds $5 \mathrm{~cm}$ or in the presence of friable tissues, a strip of autologous pericardium is used to reinforce the suture line (Fig. 1). Valvular competence is tested by infusion of saline solution with a syringe through the valve from the right atrium or by means of perioperative transesophageal echocardiography.

Echocardiographic Doppler assessment. This technique was performed before the operation and at follow- up. End-diastolic ventricular diameters and left ventricular ejection fraction were obtained. The maximal diameter of the tricuspid anulus was measured in a long-axis view of the right ventricle during systole. The severity of TR was graded on a semiquantitative scale from 0 to $4+$ according to the maximal regurgitant jet detected by Doppler color ultrasound into the right atria: $1+$ indicates that the jet extended immediately behind the tricuspid valve; $2+$ indicates extension up to one third of the length of the right atrium; $3+$ up to two thirds; and $4+$ more that two thirds into the right atrium. Continuous-wave Doppler ultrasonography was used to estimate the systolic pulmonary arterial pressure on the basis of the peak of TR flow velocity and also to determine the diastolic transtricuspid pressure gradient (TP). ${ }^{3}$ Data are expressed as mean \pm standard deviation.

Results. Two patients died $(6 \%)$ in the perioperative period, one of septic shock and the other as a result of respiratory insufficiency after reoperation for a sternal dehiscence. One patient needed a temporal pacemaker for a transitory atrioventricular block. Survivors were discharged from the hospital at $9 \pm 3$ days. At 3 months one patient $(3 \%)$ who had had an additional triple coronary bypass died suddenly. At follow-up, the 31 survivors (91\%) were in NYHA functional class I-II, 27 in class I, and 4 in class II. No patient required reoperation for recurrent TR or left-sided valve dysfunction. Echocardiographic Doppler examination showed that end-diastolic 


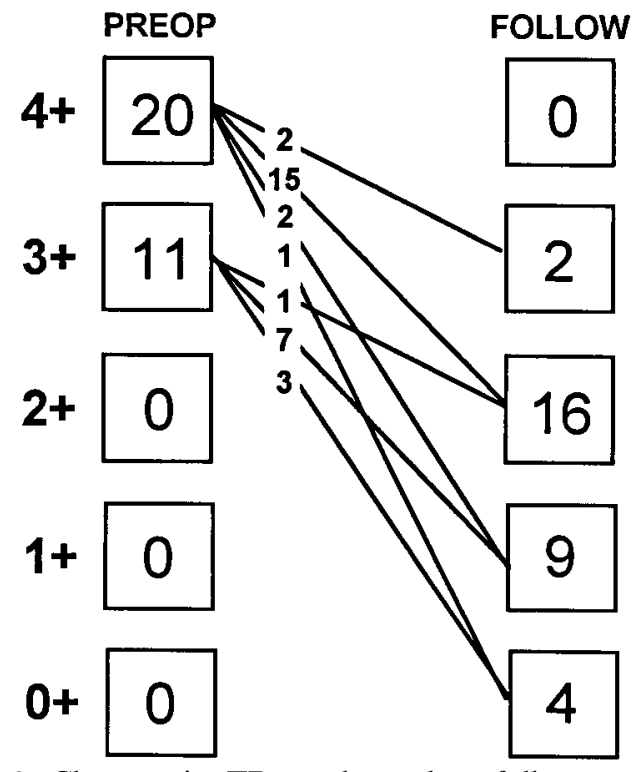

Fig. 2. Changes in $T R$ grade at late follow-up in 31 patients who underwent successful TA.

right ventricular size reduced from $32 \pm 8 \mathrm{~mm}$ before the operation to $28 \pm 6 \mathrm{~mm}$ at follow-up $(p<0.03)$ and systolic pulmonary arterial pressure from $53 \pm 14 \mathrm{~mm} \mathrm{Hg}$ to $43 \pm 12 \mathrm{~mm} \mathrm{Hg}(p<0.007)$. The enlarged anulus before TA reduced from a preoperative diameter of $40 \pm$ $8 \mathrm{~mm}$ to $26 \pm 4 \mathrm{~mm}(p<0.0005)$. Doppler ultrasound revealed an improvement in the degree of TR in all survivors (Fig. 2). No detectable TR was evidenced in 4 patients $(13 \%)$, grade $1+$ was seen in $9(29 \%)$, grade $2+$ in $16(52 \%)$, and grade $3+$ in the remaining $2(6 \%)$. None had a grade $4+$ TR. Continuous Doppler assessment of right ventricular inflow revealed a mean $\Delta \mathrm{TP}$ of $1.5 \pm 0.9$ $\mathrm{mm} \mathrm{Hg}: 1 \mathrm{~mm} \mathrm{Hg}$ or less in 17 patients $(55 \%), 2 \mathrm{~mm} \mathrm{Hg}$ in $12(39 \%)$, and 3 and $5 \mathrm{~mm} \mathrm{Hg}$, respectively, in the remaining 2 patients (6\%). There was no significant correlation between changes in pulmonary artery pressure and TR $(r=-0.42, p=0.07)$ and between tricuspid annular diameter and the residual $\Delta \mathrm{TP}(r=-0.03, p=$ $0.85)$.

Discussion. Annuloplasties involving bicuspidization of the tricuspid valve, such as the Kay technique, have been abandoned because they may lead to shortening of the annular circumference, persistent TR, or continuous annular dilatation with recurrence of TR. The Carpentier ring and De Vega annuloplasty have improved the surgical results considerably and are now widely used. The former selectively plicates the anulus by means of interrupted sutures, thus distributing the holding forces evenly over the entire circumference. However, it requires the use of a foreign body and does not preserve the shape and physiologic changes of the tricuspid orifice during the cardiac cycle, resulting in flow abnormalities and risk of dehiscence. In addition, a $\Delta \mathrm{TP}$ from 2 to $9 \mathrm{~mm} \mathrm{Hg}$ (mean $4.3 \pm 1.3 \mathrm{~mm} \mathrm{Hg}$ ) is observed in $33 \%$ of patients. ${ }^{4}$ The use of circumferential sutures with De Vega's technique may result in a semicircular deformation of the orifice and infolding of the leaflet tissue. Moreover, centripetal forces of the suture may cause tearing of the anterior anulus. Although this technique restores valvular competence in most patients, it may lead to some degree of right ventricular inflow obstruction. Thus in $50 \%$ of patients Haerten and associates ${ }^{5}$ found a residual $\Delta$ TP from 2 to $7.8 \mathrm{~mm} \mathrm{Hg}$. Cohn ${ }^{6}$ introduced a limited posterior TA using a single double-armed suture that plicates the posterior half of the anterior leaflet anulus and the whole base of the posterior leaflet. However, the use of a single suture may also produce circular deformation of the anulus, leaving the portion of the septal leaflet affected by the enlargement of the posteroseptal commissure without reinforcement. Cohn recommends a prosthetic ring for severe TR. The anatomic studies of Deloche and coworkers ${ }^{7}$ suggested that functional TR is related to the asymmetric dilatation of the tricuspid valve, which mainly affects the posteroexternal half of the tricuspid circumference. These anatomic changes are explained by the weakness of the connective tissue in this area. On the basis of this concept, we used two tangential sutures to reinforce the weakest area of the anulus. Crossing them at the base of the posterior leaflet further strengthens this weakest point. In our series, applying this technique reduced the dilated anulus to almost a normal diameter size and preserved the structure of the valves. The efficacy of the procedure is manifested by the reduction of TR in all survivors (Fig. 2). This procedure was also successfully used in those patients who had had recurrence of TR after De Vega's annuloplasty. In addition to the persistence or recurrence of TR, a significant postoperative $\Delta \mathrm{TP}$ may also cause right ventricular failure and venous congestion. ${ }^{4}$ In our series, most of the patients had either a minor inflow obstruction or no inflow obstruction, thus reducing the risk of right-sided failure. Concomitantly, all patients showed an improvement in functional status. During the period of followup, no patient needed reoperation for exacerbation or recurrence of TR.

In summary, our study presents a TA technique that applies a limited posterior crossed suture annuloplasty for correction of functional TR. The procedure is simple and rapid to perform. Our experience shows that it is efficient in reducing TR with minor residual gradient. However, further studies in a larger series are needed to confirm our results.

\section{REFERENCES}

1. Duran CMG, Pomar JL, Colman T, Figueroa A, Revuelta JM, Ubago JL. Is tricuspid valve repair necessary? J Thorac Cardiovasc Surg 1980;80:849-60.

2. Rivera R, Duran E, Ajuria M. Carpentier's flexible ring versus De Vega's annuloplasty. J Thorac Cardiovasc Surg 1985;89: 196-203.

3. Martí V, Carreras F, Borrás X, Pons-Lladó G. Doppler echocardiographic findings in normal functioning mechanical St. Jude Medical and Björk-Shiley mechanical prostheses in the tricuspid valve position. Am J Cardiol 1991;67:307-9.

4. Lambertz H, Minale C, Flachskampf FA, Zander M, Bardos 
P, Messmer BJ, et al. Long-term follow-up after Carpentier tricuspid valvuloplasty. Am Heart J 1989;117:61522.

5. Haerten K, Seipel L, Loogen F, Herzer J. Hemodynamic studies after De Vega's tricuspid annuloplasty. Circulation 1978;58(Suppl):I28-33.

6. Cohn LH. Tricuspid regurgitation secondary to mitral valve disease: when and how to repair. J Card Surg 1994;9(suppl): 237-41.

7. Deloche A, Guerinon J, Fabiani JN, Morillo F, Caramanian M, Carpentier A, et al. Étude anatomique des valvulopathies rhumatismales tricuspidiennes. Application à l'étude des différentes valvuloplasties. Ann Chir Thorac Cardiovasc 1973;12: 343-9. 